\title{
Association between Nightlife Goers' Likelihood of an Alcohol Use Disorder and Their Preferred Bar's Closing Time: A Cross-Sectional Observational Study in Perth, Australia
}

\author{
William Gilmore ${ }^{1, *(\mathbb{D}}$, Martyn Symons ${ }^{1}\left(\mathbb{D}\right.$, Wenbin Liang ${ }^{2}$, Kathryn Graham ${ }^{3}$, Kypros Kypri ${ }^{4}$, Peter Miller ${ }^{5}(\mathbb{C}$ \\ and Tanya Chikritzhs ${ }^{1}$ (I) \\ 1 National Drug Research Institute and enAble Institute, Faculty of Health Sciences, Curtin University, \\ Perth, WA 6845, Australia; Martyn.Symons@curtin.edu.au (M.S.); T.N.Chikritzhs@curtin.edu.au (T.C.) \\ 2 School of Public Health, Fujian Medical University, Fuzhou 350108, China; wenbin_liang@fjmu.edu.cn \\ 3 Institute for Mental Health Policy Research, Centre for Addiction and Mental Health, \\ Toronto, ON M5S 2S1, Canada; kgraham@uwo.ca \\ 4 School of Medicine and Public Health, University of Newcastle, Callaghan, NSW 2308, Australia; \\ kypros.kypri@newcastle.edu.au \\ 5 Centre for Drug use, Addictive and Anti-social Behaviour Research, Deakin University, \\ Geelong, VIC 3220, Australia; peter.miller@deakin.edu.au \\ * Correspondence: william.gilmore@curtin.edu.au
}

check for updates

Citation: Gilmore, W.; Symons, M.; Liang, W.; Graham, K.; Kypri, K.; Miller, P.; Chikritzhs, T. Association between Nightlife Goers' Likelihood of an Alcohol Use Disorder and Their Preferred Bar's Closing Time: A

Cross-Sectional Observational Study in Perth, Australia. Int. J. Environ. Res. Public Health 2021, 18, 13040. https://doi.org/10.3390/ ijerph182413040

Academic Editor: Paul B. Tchounwou

Received: 9 November 2021 Accepted: 8 December 2021 Published: 10 December 2021 Corrected: 5 August 2022

Publisher's Note: MDPI stays neutral with regard to jurisdictional claims in published maps and institutional affiliations.

Copyright: (c) 2021 by the authors. Licensee MDPI, Basel, Switzerland. This article is an open access article distributed under the terms and conditions of the Creative Commons Attribution (CC BY) license (https:// creativecommons.org/licenses/by/ $4.0 /)$.

\begin{abstract}
Introduction and aims: Associations between longer-term alcohol-related conditions and licensed outlet trading hours are not well understood. We investigated the association between nightlife-goers' likelihood of an alcohol use disorder (AUD) and their preference for bars with special permits to remain open 'late' (i.e., spent more time there compared to any other venue) until 2 a.m. or 3 a.m. (Friday; Saturday) or midnight (Sunday) compared to bars with 'standard' closing times of midnight (Friday; Saturday) or 10 p.m. (Sunday). Design and methods: A cross-sectional observational study was conducted in four major nightlife areas of Perth, Australia, in 2015-2016. We conducted weekend street intercept surveys outside bars between 8 p.m. and 3 a.m. and screened participants who reported alcohol use prior to the survey and spent more time in a bar than any other venue type $(n=667)$ regarding their past year drinking pattern using AUDIT-C $(n=459)$. We used gender-specific logistic regression models to estimate associations between AUDIT-C categories (1-4, low risk; 5-7, hazardous; 8-12, active AUD) and preference for bars with different closing times (late vs. standard). Results: A large proportion of participants were hazardous drinkers or had active AUD (83\% males; 65\% females), and over half preferred a late to a standard closing bar. We found evidence of a positive association between preference for late closing bars and hazardous drinking females $(\mathrm{OR}=3.48 ; 95 \%$ CI 1.47-8.23; $p=0.01)$, but not for females with active AUD, male hazardous drinkers, nor males with active AUD. Discussion and conclusions: Our study adds new evidence on associations between likelihood of AUD among nightlife-goers and trading hours. With increasing international relaxation of trading hours, evidence that late closing bars may be preferred by hazardous drinking females will be of concern to policymakers wanting to curb alcohol-related harms in the community.
\end{abstract}

Keywords: nightlife-goers; bars; on-trade licensed outlets; trading hours; closing times; AUDIT-C; alcohol use disorders; alcohol policy

\section{Introduction}

In countries where alcohol is a legal and regulated product, government control over availability is most frequently exercised through taxation, minimum legal purchase age, and a licensing system for production, wholesale and retail-regulating how, when and where outlets operate. Decades of accumulated international research, predominantly from North America, Northern Europe and Australasia, have identified that restrictions 
on alcohol's economic (i.e., retail price relative to disposable income) and physical (e.g., numbers of outlets, trading hours) availability are key to effectively reducing populationlevel alcohol consumption and related harms [1].

Availability theory suggests that greater availability will affect harm by affecting the distribution of drinking behaviors, and those harms will differ by population subgroups according to their drinking patterns and behaviors [2]. In response to changes in availability, changes in underlying drinking patterns in a population may lead to changes across a range of alcohol-related harms. For instance, research distinguishes between heavy episodic drinking that results in increased risk of shorter-term harms (e.g., injury from road traffic crashes and violence) and regular heavy use that results in increased risk of longer-term harms (e.g., alcohol dependence and liver cirrhosis) [3].

Studies of alcohol availability effects, particularly physical availability, such as outlet density and trading hours, have tended to focus on shorter-term harms (e.g., assault). By comparison, physical availability effects on potential longer-term harms, such as risk of alcohol use disorders (AUD), have been less well explored. In Australia, for instance, only two outlet density studies have examined longer-term outcomes. A longitudinal study from Victoria found off-trade outlet density was positively associated with hospitalization rates for longer-term alcohol-related conditions [4], and a cross-sectional study from Western Australia found patients' residential proximity to off-trade outlets was associated with increased risk of secondary care contact for anxiety, stress and depression [5].

Systematic reviews have generally concluded that even relatively small extensions or restrictions applied to on-trade (where alcohol is consumed on the premises e.g., bars, nightclubs) or off-trade (where alcohol is consumed elsewhere, e.g., liquor stores, supermarkets) outlet trading hours can change population-level alcohol consumption and related harms [6-12]. Moreover, a meta-analysis of six natural experiments that investigated associations between off-trade days of alcohol sale and per capita consumption from North America and Sweden, found an additional day of alcohol sale was associated with a 3.4\% increase in per capita consumption [13].

There are few studies of the associations between longer-term alcohol-related problems and licensed outlet trading hours. One German controlled interrupted time series analyses evaluating a state's ban on alcohol sales from off-trade outlets between 10 p.m. and 5 a.m. found reductions in hospitalizations for mental and behavioral disorders due to use of alcohol (ICD10 code: F10; includes acute intoxication, harmful use and dependence) in both male and female adolescents and young adults in the post intervention period, though the effect on males was stronger [14]. To our knowledge, only one study has investigated the association between likelihood of AUD and alcohol outlet trading hours. Conducted in Perth, Australia, almost 40 years ago, the study compared drinkers at bars opening at 6 a.m. or 7 a.m. with drinkers at bars opening later at 10 a.m. Using an abbreviated form of the Michigan Alcoholism Screening Test, the study found that males who drank at early opening pubs were more likely to obtain scores indicative of problem drinking compared to males who drank at later opening bars [15].

Despite a narrowing gap between males and females in terms of their levels of alcohol consumption in Australia, there are still marked differences in their drinking patterns from national surveys of the general population [16] and from national surveys of nightlifegoers [17]. Therefore, it is important to consider possible gender differences in analyses of availability and alcohol use. We investigated the association between likelihood of AUD among nightlife-goers who went 'out' drinking in Perth, Australia, and their preference for bars with different closing times (late vs. standard; spent more time in a late or standard bar compared to any other venue). We hypothesized that those with a drinking pattern indicating hazardous use or active AUD would be more likely to prefer bars with late closing hours to standard closing bars compared to low risk drinkers, and that there would be difference between males and females for these associations. To our knowledge, this is the first nightlife study to investigate whether past year alcohol consumption patterns among nightlife-goers are associated with the trading hours of their preferred bars. 


\section{Methods}

\subsection{Street Intercept Surveys}

Trained teams of between six and 12 researchers conducted street intercept surveys from November 2015 to April 2016 in metropolitan Perth's four main nightlife precincts: Perth City (five sessions); Northbridge (five sessions); Leederville (two sessions); Fremantle (one session). We avoided major events and public holidays when atypical drinking sessions may occur (e.g., New Year's Eve, Australia Day). Surveys took place in public spaces between 8 p.m. and 3 a.m. on either a Friday (five sessions) or Saturday (six sessions) and between 8 p.m. and midnight on a Sunday (two sessions). To approximate a random sample, field workers invited every third person who walked past them to participate. Field workers recorded non-responses as declines to participate only after a person had engaged with them and had the purpose of the study explained to them. Overall, we achieved a response rate of $89 \%$. Several studies of substance use in nightlife areas have employed a street intercept approach, for example, $[18,19]$, and it has been shown to be effective in recruiting samples of nightlife-goers [20]. We selected survey locations strategically using DLGSCI information, bar websites and Google Maps ${ }^{\mathrm{TM}}$ to ensure gender-specific minimum quotas of 200 each for nightlife-goers preferring a late or standard closing bar.

Field workers delivered the survey instrument using Tap Forms ${ }^{\mathrm{TM}}$ on smartphones which automatically recorded date and time of survey. After gaining informed consent, participants self-reported gender, birth year and usual occupation. Field workers then asked participants a series of questions related to their drinking behaviors that night prior to survey including: Had they drunk any alcohol? How long had they been drinking? Had they been drinking at licensed venues? Had they been drinking elsewhere prior to drinking at licensed venues (i.e., pre-drinking)? Had they drunk energy drinks? Was it a typical night out for them?

If participants had been drinking at licensed venues, field workers asked them the names of the venues they had attended and about how much time had they spent at each. As described below, we used this question to define whether their preferred bar's hours were late or standard closing. Field workers then asked participants the three Alcohol Use Disorder Identification Test-Consumption (AUDIT-C) questions, assessing frequency of drinking, typical number of drinks consumed on a drinking occasion, and frequency of six or more standard drinks, all over the past year [21]. AUDIT-C is a quick, simple, reliable and well validated tool to screen for hazardous drinking or active AUD based on past year drinking pattern [22-25] and has been used in research studies outside of clinical settings previously, for example, [26].

\subsection{Bar's Closing Times}

The Perth liquor licensing system allows bars to apply to the Department of Local Government, Sport and Cultural Industries (DLGSCI) for extended trading permits that enable late night (or early morning) alcohol sales. At the time of the current study, standard closing for bars was midnight Monday to Saturday and 10 p.m. Sunday. However, after application and approval for a closing time extension, some were permitted to trade up until 2 a.m. or 3 a.m. Monday to Saturday and to midnight Sunday (late closing).

At the commencement of data collection, legislation change in local liquor licensing was implemented at very short notice [27]. From 20 November 2015, all bars (i.e., not just those with special permits) were allowed to trade up to midnight on Sunday nights rather than closing at 10 p.m. Surveys took place on two Sunday nights in the early months of the study (22 November, 20 December), and because we observed little uptake of these relaxed trading hours on the ground we did not change what constituted late (midnight) vs. standard (10 p.m.) closing bars for these dates. We halted Sunday surveys at the end of 2015 due to the potential for bars to start taking up the newly relaxed trading hours and because it was more difficult to meet survey quotas on quieter Sunday nights. 


\subsection{Survey Data}

Regardless of the time of survey, participants who reported alcohol use may not have visited a licensed venue at all or may have visited a number of different venues on their night out (including restaurants, both standard and late closing bars, nightclubs etc.). Participants surveyed past midnight, therefore, were not necessarily drinkers from late closing bars and vice versa. We defined participants' 'preferred venue' as where they had spent more time that night compared to other venues and assumed this is where they had probably consumed most alcohol. We coded 'preferred bars' according to whether they had standard (0) or late (1) closing using DLGSCI records and cross-checked against bar websites for currency. We found only one bar had its late trading permit revoked during the study period; in this instance bar trading status (late; standard) was coded based on date of survey and date of permit revocation.

We categorized AUDIT-C scores into three groups using the same raw score cut-offs for males and females: $1-4$, low risk drinker; $5-7$, hazardous drinker; $8-12$, drinker with active AUD [28]. We estimated participant age using date of survey and year of birth then categorized into four groups: $18-21 ; 22-25 ; 26-29 ; \geq 30$. We classified occupation according to the Australian and New Zealand Standard Classification of Occupations (plus an 'Other' category to capture students, stay-at-home parents, unemployed etc.) [29] and grouped as follows: manager/professional; technician/trade/laborer; community/personal service; clerical/administrative/sales; other. We dichotomized time of survey into 'before midnight' and 'midnight and after', reflecting the distinction between late and standard closing bars. In order to reflect typical night-time drinking occasions, we categorized day of survey (i.e., Friday, Saturday or Sunday) according to when data collection sessions were initiated, for example, surveys undertaken between 10 p.m. Friday night and 2 a.m. the following morning were all considered a 'Friday' night survey.

\subsection{Statistical Analysis}

We used Pearson's chi-square tests and independent samples t-tests to explore bivariate associations (Table 1). We used multivariable logistic regression models to investigate whether participant likelihood of AUD was associated with preferring a standard or late closing bar (Table 2). We ran two gender-specific models and adjusted for a range of potential confounders including: age, occupation, day of survey, time of survey, drinking session duration, whether it was a typical night out, pre-drinking and energy drink use using a backward stepwise selection approach. Hosmer and Lemeshow statistics assessed the models' goodness-of-fit. We used SPSS Statistics v27.0 (IBM Corp, Armonk, NY, USA) for all analyses [30].

\subsection{Ethics}

We conducted this study in accordance with the National Statement on Ethical Conduct in Human Research and the Human Research Ethics Committees at Curtin University approved it (HR154/2015). Participants provided informed consent to field workers who recorded responses in an electronic data collection smartphone application. 
Table 1. Gender-specific descriptive statistics and bivariate analyses for participant and survey characteristics by participants' preferred bar's closing time.

\begin{tabular}{|c|c|c|c|c|c|c|c|c|c|c|}
\hline \multirow{3}{*}{$\begin{array}{l}\text { Variables }^{ \pm} \\
\text {Participant characteristics }\end{array}$} & \multicolumn{4}{|c|}{ Male } & \multicolumn{6}{|c|}{ Female } \\
\hline & \multicolumn{2}{|c|}{ Late } & \multicolumn{2}{|c|}{ Standard } & & \multicolumn{2}{|c|}{ Late } & \multicolumn{2}{|c|}{ Standard } & \\
\hline & $n$ & $\%$ & $n$ & $\%$ & & $n$ & $\%$ & $n$ & $\%$ & \\
\hline $\begin{array}{l}\text { AUDIT-C } \\
1-4 \text { (low risk) } \\
5-7 \text { (hazardous) } \\
8-12 \text { (active AUD) } \\
\text { Total }\end{array}$ & $\begin{array}{c}27 \\
67 \\
77 \\
171\end{array}$ & $\begin{array}{c}16 \\
39 \\
45 \\
100\end{array}$ & $\begin{array}{l}27 \\
58 \\
55 \\
140\end{array}$ & $\begin{array}{c}19 \\
41 \\
39 \\
100\end{array}$ & $\begin{array}{c}\chi^{2}(2)=1.2 \\
p=0.54\end{array}$ & $\begin{array}{l}23 \\
48 \\
14 \\
85\end{array}$ & $\begin{array}{l}27 \\
56 \\
16 \\
100\end{array}$ & $\begin{array}{l}29 \\
19 \\
15 \\
63\end{array}$ & $\begin{array}{c}46 \\
30 \\
24 \\
100\end{array}$ & $\begin{array}{c}\chi^{2}(2)=10.2 \\
p=0.01\end{array}$ \\
\hline $\begin{array}{l}\text { Age } \\
18-21 \\
22-25 \\
26-29 \\
\geq 30 \\
\text { Total }\end{array}$ & $\begin{array}{r}46 \\
73 \\
56 \\
76 \\
251\end{array}$ & $\begin{array}{c}18 \\
29 \\
22 \\
30 \\
100\end{array}$ & $\begin{array}{l}24 \\
48 \\
59 \\
70 \\
201\end{array}$ & $\begin{array}{c}12 \\
24 \\
29 \\
35 \\
100\end{array}$ & $\begin{array}{c}\chi^{2}(3)=7.0 \\
p=0.07\end{array}$ & $\begin{array}{c}39 \\
41 \\
16 \\
31 \\
127\end{array}$ & $\begin{array}{l}31 \\
32 \\
13 \\
24 \\
100\end{array}$ & $\begin{array}{l}19 \\
25 \\
24 \\
18 \\
86\end{array}$ & $\begin{array}{c}22 \\
29 \\
28 \\
21 \\
100\end{array}$ & $\begin{array}{c}\chi^{2}(2)=8.2 \\
p=0.04\end{array}$ \\
\hline $\begin{array}{l}\text { Occupation } \\
\text { Manager/professional } \\
\text { Technician/trade/labourer } \\
\text { Community/personal } \\
\text { service } \\
\text { Clerical/administrative/sales } \\
\text { Other } \\
\text { Total }\end{array}$ & $\begin{array}{c}83 \\
88 \\
18 \\
24 \\
31 \\
244\end{array}$ & $\begin{array}{c}34 \\
36 \\
7 \\
10 \\
13 \\
100\end{array}$ & $\begin{array}{l}77 \\
65 \\
15 \\
7 \\
33 \\
197\end{array}$ & $\begin{array}{c}39 \\
33 \\
8 \\
4 \\
17 \\
100\end{array}$ & $\begin{array}{c}\chi^{2}(4)=8.4 \\
p=0.08\end{array}$ & $\begin{array}{c}29 \\
8 \\
25 \\
28 \\
33 \\
123\end{array}$ & $\begin{array}{c}24 \\
7 \\
20 \\
23 \\
27 \\
100\end{array}$ & $\begin{array}{c}28 \\
6 \\
12 \\
22 \\
17 \\
85\end{array}$ & $\begin{array}{c}33 \\
7 \\
14 \\
26 \\
20 \\
100\end{array}$ & $\begin{array}{c}\chi^{2}(4)=3.9 \\
p=0.42\end{array}$ \\
\hline $\begin{array}{l}\text { Pre-drinking } \\
\text { No } \\
\text { Yes } \\
\text { Total }\end{array}$ & $\begin{array}{l}110 \\
140 \\
250\end{array}$ & $\begin{array}{c}44 \\
56 \\
100\end{array}$ & $\begin{array}{l}108 \\
95 \\
203\end{array}$ & $\begin{array}{c}53 \\
47 \\
100\end{array}$ & $\begin{array}{c}\chi^{2}(1)=3.8 \\
p=0.05\end{array}$ & $\begin{array}{c}52 \\
75 \\
127\end{array}$ & $\begin{array}{c}41 \\
59 \\
100\end{array}$ & $\begin{array}{l}53 \\
33 \\
86\end{array}$ & $\begin{array}{c}62 \\
38 \\
100\end{array}$ & $\begin{array}{c}\chi^{2}(1)=8.8 \\
p<0.01\end{array}$ \\
\hline $\begin{array}{l}\text { Energy drink use } \\
\text { No } \\
\text { Yes } \\
\text { Total }\end{array}$ & $\begin{array}{c}205 \\
46 \\
251\end{array}$ & $\begin{array}{c}82 \\
18 \\
100\end{array}$ & $\begin{array}{l}185 \\
18 \\
203\end{array}$ & $\begin{array}{c}91 \\
9 \\
100\end{array}$ & $\begin{array}{c}\chi^{2}(1)=8.3 \\
p<0.01\end{array}$ & $\begin{array}{l}110 \\
17 \\
127\end{array}$ & $\begin{array}{c}87 \\
13 \\
100\end{array}$ & $\begin{array}{l}79 \\
7 \\
86\end{array}$ & $\begin{array}{c}92 \\
8 \\
100\end{array}$ & $\begin{array}{c}\chi^{2}(1)=1.4 \\
p=0.24\end{array}$ \\
\hline $\begin{array}{l}\text { Was it a typical night out? } \\
\text { No, usually smaller } \\
\text { No, usually bigger } \\
\text { Yes } \\
\text { Total }\end{array}$ & $\begin{array}{c}44 \\
28 \\
62 \\
134\end{array}$ & $\begin{array}{c}33 \\
21 \\
46 \\
100\end{array}$ & $\begin{array}{l}32 \\
27 \\
68 \\
127\end{array}$ & $\begin{array}{c}25 \\
21 \\
54 \\
100\end{array}$ & $\begin{array}{c}\chi^{2}(2)=2.0 \\
p=0.37\end{array}$ & $\begin{array}{l}20 \\
13 \\
46 \\
79\end{array}$ & $\begin{array}{c}25 \\
16 \\
58 \\
100\end{array}$ & $\begin{array}{l}16 \\
16 \\
27 \\
59\end{array}$ & $\begin{array}{c}27 \\
27 \\
46 \\
100\end{array}$ & $\begin{array}{c}\chi^{2}(2)=2.9 \\
p=0.24\end{array}$ \\
\hline $\begin{array}{l}\text { Drinking session duration } \\
\text { (hours) }\end{array}$ & 246 & $\begin{array}{c}\text { Mean } \\
(\mathrm{SD}) \\
4.8(2.7)\end{array}$ & 198 & $\begin{array}{c}\text { Mean } \\
(\mathrm{SD}) \\
5.0(2.5)\end{array}$ & $\begin{array}{c}\mathrm{t}(442)=0.9 \\
p=0.31\end{array}$ & 126 & $\begin{array}{c}\text { Mean } \\
(\mathrm{SD}) \\
4.5(2.3)\end{array}$ & 86 & $\begin{array}{c}\text { Mean } \\
(\mathrm{SD}) \\
4.4 \\
(2.0) \\
\end{array}$ & $\begin{array}{c}t(210)=-0.3 \\
p=0.48\end{array}$ \\
\hline Survey characteristics & $n$ & $\%$ & $n$ & $\%$ & & $n$ & $\%$ & $n$ & $\%$ & \\
\hline $\begin{array}{l}\text { Day } \\
\text { Friday } \\
\text { Saturday } \\
\text { Sunday } \\
\text { Total }\end{array}$ & $\begin{array}{c}108 \\
119 \\
24 \\
251\end{array}$ & $\begin{array}{c}43 \\
47 \\
10 \\
100\end{array}$ & $\begin{array}{l}48 \\
118 \\
37 \\
203\end{array}$ & $\begin{array}{c}24 \\
58 \\
18 \\
100\end{array}$ & $\begin{array}{c}\chi^{2}(2)=21.0 \\
p<0.001\end{array}$ & $\begin{array}{c}52 \\
64 \\
11 \\
127\end{array}$ & $\begin{array}{c}41 \\
50 \\
9 \\
100\end{array}$ & $\begin{array}{c}19 \\
62 \\
5 \\
86\end{array}$ & $\begin{array}{c}22 \\
72 \\
6 \\
100\end{array}$ & $\begin{array}{c}\chi^{2}(2)=10.1 \\
p=0.01\end{array}$ \\
\hline $\begin{array}{l}\text { Time } \\
\text { Before midnight } \\
\text { Midnight and after } \\
\text { Total }\end{array}$ & $\begin{array}{l}127 \\
124 \\
251\end{array}$ & $\begin{array}{c}51 \\
49 \\
100\end{array}$ & $\begin{array}{l}134 \\
69 \\
203\end{array}$ & $\begin{array}{c}66 \\
34 \\
100\end{array}$ & $\begin{array}{c}\chi^{2}(1)=10.9 \\
p=0.001\end{array}$ & $\begin{array}{c}60 \\
67 \\
127\end{array}$ & $\begin{array}{c}47 \\
53 \\
100\end{array}$ & $\begin{array}{l}52 \\
34 \\
86\end{array}$ & $\begin{array}{c}60 \\
40 \\
100\end{array}$ & $\begin{array}{c}\chi^{2}(1)=3.6 \\
p=0.06\end{array}$ \\
\hline
\end{tabular}

${ }^{ \pm}$Small or big night out are colloquialisms regarding level of perceived intoxication. 
Table 2. Results from two gender-specific logistic regression models: Association between AUDIT-C category and participants' preferred bar's closing time (late $=1$; standard $=0$ ) adjusting for survey and participant characteristics ${ }^{ \pm}$.

\begin{tabular}{|c|c|c|c|c|c|c|c|c|c|c|}
\hline \multirow{2}{*}{$\begin{array}{l}\text { Variables }^{ \pm} \\
\text {Participant characteristics }\end{array}$} & \multicolumn{5}{|c|}{ Male $(n=306)$} & \multicolumn{5}{|c|}{ Female $(n=148)$} \\
\hline & $n$ & OR & LCI & UCI & $p$-Value & $n$ & OR & LCI & UCI & $p$-Value \\
\hline \multicolumn{11}{|l|}{ AUDIT-C } \\
\hline 1-4 (low risk) [Ref] & 54 & & & & & 52 & & & & \\
\hline 5-7 (hazardous) & 121 & 1.06 & 0.54 & 2.09 & 0.87 & 67 & 3.48 & 1.47 & 8.23 & $<0.01$ \\
\hline 8-12 (active AUD) & 131 & 1.31 & 0.66 & 2.62 & 0.44 & 29 & 1.23 & 0.43 & 3.52 & 0.70 \\
\hline \multicolumn{11}{|l|}{ Age } \\
\hline $18-21$ & 57 & 2.82 & 1.26 & 6.33 & 0.01 & 39 & 0.96 & 0.33 & 2.78 & 0.94 \\
\hline $22-25$ & 84 & 1.48 & 0.78 & 2.81 & 0.23 & 51 & 0.73 & 0.26 & 2.06 & 0.55 \\
\hline $26-29$ & 76 & 1.09 & 0.57 & 2.08 & 0.80 & 25 & 0.13 & 0.04 & 0.49 & $<0.01$ \\
\hline$\geq 30$ [Ref] & 89 & & & & & 33 & & & & \\
\hline \multicolumn{11}{|l|}{ Occupation } \\
\hline Manager/professional & 100 & 2.11 & 0.96 & 4.65 & 0.07 & & & & & \\
\hline Technician/trade/labourer & 115 & 2.02 & 0.96 & 4.25 & 0.06 & & & & & \\
\hline $\begin{array}{l}\text { Community/personal } \\
\text { service }\end{array}$ & 20 & 1.22 & 0.41 & 3.62 & 0.72 & & & & & \\
\hline Clerical/administrative/sales & 21 & 3.46 & 1.09 & 10.94 & 0.03 & & & & & \\
\hline Other [Ref] & 50 & & & & & & & & & \\
\hline \multicolumn{11}{|l|}{ Survey characteristics } \\
\hline \multicolumn{11}{|l|}{ Day } \\
\hline Friday & 111 & 1.92 & 1.14 & 3.22 & 0.01 & 53 & 3.22 & 1.43 & 7.26 & $<0.01$ \\
\hline Saturday [Ref] & 163 & & & & & 86 & & & & \\
\hline Sunday & 32 & 0.58 & 0.26 & 1.28 & 0.18 & 9 & 2.99 & 0.60 & 15.04 & 0.18 \\
\hline
\end{tabular}

Male model: Hosmer and Lemeshow $\chi^{2}(8)=10.3, p=0.25$. Female model: Hosmer and Lemeshow $\chi^{2}(7)=1.1, p=0.99$. OR: Odds ratio. L/UCI: $95 \%$ lower/upper confidence interval. [Ref]: Reference group. ${ }^{ \pm}$Time of survey, duration of drinking session, pre-drinking, energy drink use and whether it was a typical night out were non-contributing variables in both models and removed in the backward stepwise selection approach. Occupation was a non-contributing variable in the female model and was removed in the backward stepwise selection approach.

\section{Results}

As shown in Table 1, of the 667 participants who reported alcohol use at a licensed venue and preferred a bar to other venue types, 459 completed the AUDIT-C. A large proportion of participants were hazardous drinkers (40\% males; $45 \%$ females) or had active AUD (42\% males; $20 \%$ females). Over half of male and female participants preferred a late closing bar to a standard closing bar. Gender-specific bivariate analyses indicated evidence of association between AUDIT-C and bar closing time for females but not males. Hazardous drinking females preferred late closing bars over standard closing bars, but for low risk drinking females and females with active AUD the association was the opposite. Age was associated with preferred bar for female participants, with those in all age groups except 26-29 more likely to prefer later closing. Participants were from a range of occupations, but there was no evidence of association between occupation and bar preference. For males and females, pre-drinking was more common among those preferring late closing bars. Less than a fifth of participants reported energy drink use, with males who used energy drinks more likely to prefer late closing bars. Half reported that it was not a typical night out for them, with males reporting a non-typical night out more likely to prefer late closing bars. In terms of survey characteristics, preference for late closing bars was more likely among those surveyed on Friday nights than on Saturday nights and more likely among those surveyed after midnight than before midnight.

Hosmer and Lemeshow statistics raised no concerns about the goodness-of-fit of the two logistic regression models (Table 2). Model results indicated no evidence of association between males' AUDIT-C category and their preferred bar's closing time. For male participants, the preference for late-closing bars was associated with the following: 
the youngest age group (age 18-21); clerical occupations (compared to 'other'); and the survey occurring on Friday night.

Model results for female participants indicated an association between a preference for late closing bars and hazardous drinking $(\mathrm{OR}=3.48 ; 95 \% \mathrm{CI} 1.47-8.23 ; p=0.01)$ compared to low risk drinking, but not for active AUD. For females, there was also a positive association between a preference for late closing bars and being surveyed on Friday night compared to Saturday night, but a negative association with being 26-29 years old compared to 30 years and older.

\section{Discussion}

Female hazardous drinkers were more likely to prefer a late closing bar when compared to female low risk drinkers. We found no evidence to support our hypothesis of a positive association between preference for late closing bars and females with active AUD, male hazardous drinkers or males with active AUD.

International research has demonstrated positive associations between licensed outlet trading hours and population-level per capita alcohol consumption [13], and both male and female adolescent and young adult hospitalizations for mental and behavioral disorders due to use of alcohol (encompassing shorter-term and longer-term harms) [14]. The only study that we are aware of that has focused specifically on the relationship between AUD and patron attendance at bars with extended trading hours found a positive association for males (females were not included in the study) [15]. However, that study investigated the association for earlier opening hours rather than later closing as in the present study. Our study was partly consistent with those findings but only for female hazardous drinkers (not for the heaviest drinking females nor male participants at all). Sample size for females with active AUD was smaller than for the other AUDIT-C categories and this may have affected statistical power. Gender differences in our findings may be related to other characteristics of bars themselves that we were unable to adjust for, for example, in terms of their target audience, marketing and entertainment. The lack of evidence for association for males may also be explained by the high proportion who said it was not a typical night out. Thus, male attendance (or lack of attendance) at a late closing bar on the night of survey may have been less reflective of their usual pattern.

Licensed outlets' closing times and their associations with harm are a policy issue highly relevant to liquor licensing, health and law enforcement authorities and to the general public.

Our results are directly relevant for Western Australian decision makers in the wake of state-wide Sunday closing time relaxation (from $10 \mathrm{pm}$ to midnight) for bars in 2015 (see methods) and in light of proposals to introduce Sunday trading for liquor stores in regional areas across the state (currently restricted except for cases where extended trading time permits are held), both recommendations coming out of a review of the Western Australian Liquor Control Act in 2013 [26]. At present, applications and decisions relating to extended trading time permits for bars are made by the Department of Local Government, Sport and Cultural Industries on an ad hoc basis, likely with inconsistent reference to research evidence. As international and even national research findings can often be interpreted as unrelated to local contexts, this study may help to fill a local knowledge gap. As well, it may suggest more generally an important link between later closing and hazardous drinking among females.

\section{Limitations}

We made several assumptions in assigning participants to late vs. standard closing bars. We assumed that time spent in a bar was positively associated with quantity of alcohol consumed, which may not necessarily be the case. We also assumed spending most time in one venue type meant that the sum of time over the night would be in favor of that venue type, that is, participants who spent two hours in one late closing bar and one hour in each of three standard closing bars will have been assigned as preferring late closing 
bars. Furthermore, half of participants were not on a typical night out for them so may have been drinking at venues they did not typically frequent and/or may have gone home earlier or stayed out later than usual.

It is important to note that we were only able to discern evidence of cross-sectional associations between nightlife-goers' heavy drinking and their preference for late closing bars not whether heavier drinking leads to frequenting later closing bars or vice versa. The study also used self-report which may not be the most accurate measure as cognitive ability declines with alcohol intoxication [31]. Finally, our results may not be generalizable to other nightlife areas outside of Perth, Australia.

\section{Conclusions}

Our study adds new evidence to the alcohol physical availability research on associations between longer-term alcohol problems among nightlife-goers and alcohol outlet trading hours. With increasing state, national and international relaxation of trading hours for licensed outlets, evidence that preference for later closing bars is associated with hazardous drinking among females will be of concern to policymakers wanting to curb alcohol-related harms in the community.

Author Contributions: W.G.: Conceptualisation, investigation, methodology, formal analysis, project administration, supervision, writing-original draft, funding acquisition. M.S.: Methodology, writing-review \& editing. W.L.: Conceptualisation, investigation, methodology, supervision, writing—review \& editing, funding acquisition. K.G.: Conceptualisation, methodology, writingreview \& editing, funding acquisition. K.K.: Conceptualisation, methodology, writing-review \& editing, funding acquisition. P.M.: Conceptualisation, investigation, methodology, supervision, writing - review \& editing, funding acquisition. T.C.: Conceptualisation, investigation, methodology, project administration, supervision, writing-review \& editing, funding acquisition. All authors have read and agreed to the published version of the manuscript.

Funding: This study was funded by a Healthway Special Research Initiative: Alcohol Policy and Prevention Grant (24070). WG was supported by an Australian Government Research Training Program Scholarship. The National Drug Research Institute at Curtin University is supported by funding from the Australian Government under the Drug and Alcohol Program. Funders had no role in the study design, collection, analysis or interpretation of the data, writing the manuscript, or the decision to submit the paper for publication.

Institutional Review Board Statement: The study was conducted according to the guidelines of the Declaration of Helsinki, and approved by the Human Research Ethics Committees at Curtin University (protocol code HR154/2015 approved on 11/08/2015).

Informed Consent Statement: Informed consent was obtained from all subjects involved in the study.

Data Availability Statement: The data presented in this study are available on request from the corresponding author subject to ethical approval.

Acknowledgments: We would like to thank our field work coordinators Elise Gordon and Eveline Lensvelt and our team of field workers for the late nights, Nicolas Droste for your invaluable input as an investigator across the course of the study, Ashlee Curtis for your help with the first weekend of data collection, Nicole Edwards for your help in coding the dataset, and James Migro and the Liquor Licensing Enforcement Division of Western Australia Police for your support of the study.

Conflicts of Interest: P.M. has acted as a paid expert witness on behalf of a licensed venue and a security firm. Other authors declare that they have no conflict of interest.

\section{References}

1. World Health Organization. Global Status Report on Alcohol and Health; World Health Organization: Geneva, Switzerland, 2018.

2. Stockwell, T.; Gruenewald, P. Controls on physical availability of alcohol. In The Essential Handbook of Treatment and Prevention of Alcohol Problems; Heather, N., Stockwell, T., Eds.; Wiley and Sons: Hoboken, NJ, USA, 2004.

3. Sherk, A.; Stockwell, T.; Rehm, J.; Dorocicz, J.; Shield, K.D.; Churchill, S. The international model of alcohol harms and policies: A new method for estimating alcohol health harms with application to alcohol-attributable mortality in Canada. J. Stud. Alcohol Drugs 2020, 81, 339-351. [CrossRef] [PubMed] 
4. Livingston, M. Alcohol outlet density and harm: Comparing the impacts on violence and chronic harms. Drug Alcohol Rev. 2011, 30, 515-523. [CrossRef]

5. Pereira, G.; Wood, L.; Foster, S.; Haggar, F. Access to alcohol outlets, alcohol consumption and mental health. PLoS ONE 2013, 8, e53461.

6. Stockwell, T.; Chikritzhs, T. Do relaxed trading hours for bars and clubs mean more relaxed drinking? A review of international research on the impacts of changes to permitted hours of drinking. Crime Prev. Commun. Saf. 2009, 11, 153-170. [CrossRef]

7. Popova, S.; Giesbrecht, N.; Bekmuradov, D.; Patra, J. Hours and days of sale and density of alcohol outlets: Impacts on alcohol consumption and damage: A systematic review. Alcohol Alcohol. 2009, 44, 500-516. [CrossRef] [PubMed]

8. Hahn, R.A.; Kuzara, J.L.; Elder, R.; Brewer, R.; Chattopadhyay, S.; Fielding, J.; Naimi, T.S.; Toomey, T.; Middleton, J.C.; Lawrence, B.; et al. Effectiveness of policies restricting hours of alcohol sales in preventing excessive alcohol consumption and related harms. Am. J. Prev. Med. 2010, 39, 590-604. [CrossRef] [PubMed]

9. Holmes, J.; Guo, Y.; Maheswaran, R.; Nicholls, J.; Meier, P.S.; Brennan, A. The impact of spatial and temporal availability of alcohol on its consumption and related harms: A critical review in the context of UK licensing policies. Drug Alcohol Rev. 2014, 33, 515-525. [CrossRef]

10. Wilkinson, C.; Livingston, M.; Room, R. Impacts of changes to trading hours of liquor licences on alcohol-related harm: A systematic review 2005-2015. Public Health Res. Pract. 2016, 26, e2641644. [CrossRef]

11. Sanchez-Ramirez, D.C.; Voaklander, D. The impact of policies regulating alcohol trading hours and days on specific alcohol-related harms: A systematic review. Inj. Prev. 2018, 24, 94. [CrossRef] [PubMed]

12. Nepal, S.; Kypri, K.; Tekelab, T.; Hodder, R.K.; Attia, J.; Bagade, T.; Chikritzhs, T.; Miller, P. Effects of extensions and restrictions in alcohol trading hours on the incidence of assault and unintentional injury: Systematic review. J. Stud. Alcohol Drugs 2020, 81, 5-23. [CrossRef] [PubMed]

13. Sherk, A.; Stockwell, T.; Chikritzhs, T.; Andréasson, S.; Angus, C.; Gripenberg, J.; Holder, H.; Holmes, J.; Mäkelä, P.; Mills, M.; et al. Alcohol consumption and the physical availability of take-away alcohol: Systematic reviews and meta-analyses of the days and hours of sale and outlet density. J. Stud. Alcohol Drugs 2018, 79, 58-67. [CrossRef]

14. Marcus, J.; Siedler, T. Reducing binge drinking? The effect of a ban on late-night off-premise alcohol sales on alcohol-related hospital stays in Germany. J. Public Econ. 2015, 123, 55-77. [CrossRef]

15. Smith, D.I. Comparison of patrons of hotels with early opening and standard hours. Int. J. Addict. 1986, 21, 155-163. [CrossRef]

16. Australian Institute of Health and Welfare. National Drug Strategy Household Survey 2019; Drug Statistics Series No. 32. PHE 270; AIHW: Canberra, Australia, 2020.

17. Miller, P.G.; Pennay, A.; Droste, N.; Jenkinson, R.; Quinn, B.; Chikritzhs, T.; Tomsen, S.A.; Wadds, P.; Jones, S.C.; Palmer, D.; et al. Patron Offending and Intoxication in Night-Time Entertainment Districts; National Drug Law Enforcement Research Fund: Canberra, Australia, 2013.

18. Hughes, K.; Quigg, Z.; Bellis, M.A.; van Hasselt, N.; Calafat, A.; Kosir, M.; Juan, M.; Duch, M.; Voorham, L. Drinking behaviours and blood alcohol concentration in four European drinking environments: A cross-sectional study. BMC Public Health 2011, 11, 918. [CrossRef]

19. Miller, P.; Pennay, A.; Jenkinson, R.; Droste, N.; Chikritzhs, T.; Tomsen, S.; Wadds, P.; Jones, S.C.; Palmer, D.; Barrie, L.; et al. Patron offending and intoxication in night-time entertainment districts (POINTED): A study protocol. Int. J. Alcohol Drug Res.. 2013, 20, 69-76. [CrossRef]

20. Graham, K.; Bernards, S.; Clapp, J.D.; Dumas, T.M.; Kelley-Baker, T.; Miller, P.G.; Wells, S. Street intercept method: An innovative approach to recruiting young adult high-risk drinkers. Drug Alcohol Rev. 2014, 33, 449-455. [CrossRef] [PubMed]

21. Haber, P. Guidelines for the Treatment of Alcohol Problems; The Australian Department of Health: Canberra, Australian, 2009.

22. Bush, K.; Kivlahan, D.R.; McDonell, M.B.; Fihn, S.D.; Bradley, K.A. The AUDIT alcohol consumption questions (AUDIT-C): An effective brief screening test for problem drinking. Arch. Intern. Med. 1998, 158, 1789-1795. [CrossRef]

23. Dawson, D.A.; Grant, B.F.; Stinson, F.S.; Zhou, Y. Effectiveness of the derived Alcohol Use Disorders Identification Test (AUDIT-C) in screening for alcohol use disorders and risk drinking in the US general population. Alcohol. Clin. Exp. Res. 2005, 29, 844-854. [CrossRef]

24. Barry, A.E.; Chaney, B.H.; Stellefson, M.L.; Dodd, V. Evaluating the psychometric properties of the AUDIT-C among college students. J. Subst. Use 2015, 20, 1-5. [CrossRef]

25. Higgins-Biddle, J.C.; Babor, T.F. A review of the Alcohol Use Disorders Identification Test (AUDIT), AUDIT-C, and USAUDIT for screening in the United States: Past issues and future directions. Am. J. Drug Alcohol Abuse 2018, 44, 578-586. [CrossRef] [PubMed]

26. Verhoog, S.; Dopmeijer, J.M.; de Jonge, J.M.; van der Heijde, C.M.; Vonk, P.; Bovens, R.H.; de Boer, M.R.; Hoekstra, T.; Kunst, A.E.; Wiers, R.W.; et al. The use of the alcohol use disorders identification test-Consumption as an indicator of hazardous alcohol use among university students. Eur. Addict. Res. 2020, 26, 1-9. [CrossRef]

27. Independent Review Committee. Liquor Control Act 1988: Report of the Independent Review Committee; Western Australian Department of Racing Gaming and Liquor: Perth, Australia, 2013.

28. Khadjesari, Z.; White, I.R.; McCambridge, J.; Marston, L.; Wallace, P.; Godfrey, C.; Murray, E. Validation of the AUDIT-C in adults seeking help with their drinking online. Addict. Sci. Clin. Pract. 2017, 12, 2. [CrossRef] 
29. Australian Bureau of Statistics. 1220.0-ANZSCO-Australian and New Zealand Standard Classification of Occupations 2013; Version 1.3; Australian Bureau of Statistics: Canberra, Australia, 2019.

30. IBM Corp. IBM SPSS Statistics for Windows, Version 27.0; IBM Corp.: Armonk, NY, USA, 2020.

31. Gilmore, W.; Chikritzhs, T.; Stockwell, T.; Jernigan, D.; Naimi, T.; Gilmore, I. Alcohol: Taking a population perspective. Nat. Rev. Gastroenterol. Hepatol. 2016, 13, 426-434. [CrossRef] 